\title{
Fixed point results for generalized $(\alpha-\eta)-\Theta$ contractions with applications
}

\author{
Nawab Hussain ${ }^{a}$, Abdullah Eqal Al-Mazrooei ${ }^{b}$, Jamshaid Ahmad ${ }^{b, *}$ \\ ${ }^{a}$ Department of Mathematics, King Abdulaziz University, P. O. Box 80203, Jeddah 21589, Saudi Arabia. \\ ${ }^{b}$ Department of Mathematics, University of Jeddah, P.O. Box 80327, Jeddah 21589, Saudi Arabia.
}

Communicated by G. Marino

\begin{abstract}
The aim of this paper is to define generalized $(\alpha-\eta)-\Theta$ contraction and to extend the results of Jleli and Samet [M. Jleli, B. Samet, J. Inequal. Appl., 2014 (2014), 8 pages] by applying a simple condition on the function $\Theta$. We also deduce certain fixed and periodic point results for orbitally continuous generalized $\Theta$-contractions and certain fixed point results for integral inequalities are derived. Finally, we provide an example to show the significance of the investigation of this paper. (C)2017 All rights reserved.
\end{abstract}

Keywords: Fixed point, complete metric space, $\alpha$-admissible mapping.

2010 MSC: 47H10, 54H25.

\section{Introduction and preliminaries}

Banach's contraction principle [8] is one of the pivotal results of analysis. It establishes that, given a mapping $F$ on a complete metric space $(X, d)$ into itself and a constant $k \in(0,1)$ such that

$$
d(F x, F y) \leqslant k d(x, y)
$$

holds for all $x, y \in X$. Then $F$ has a unique fixed point in $X$.

Due to its importance and simplicity, several authors have obtained many interesting extensions and generalizations of the Banach contraction principle (see [1-13, 17] and references therein). In 2012, Samet et al. [21] introduced the concepts of $\alpha-\psi$-contractive and $\alpha$-admissible mappings and established various fixed point theorems for such mappings defined on complete metric spaces.

Definition 1.1 ([21]). Let $F$ be a self-mapping on $X$ and $\alpha: X \times X \rightarrow[0,+\infty)$ be a function. We say that $F$ is an $\alpha$-admissible mapping if

$$
x, y \in X, \quad \alpha(x, y) \geqslant 1 \quad \Longrightarrow \quad \alpha(F x, F y) \geqslant 1
$$

\footnotetext{
*Corresponding author

Email addresses: nhusain@kau.edu.sa (Nawab Hussain), aealmazrooei@uj.edu.sa (Abdullah Eqal Al-Mazrooei), jkhan@uj.edu.sa, jamshaid_jasim@yahoo.com (Jamshaid Ahmad)

doi:10.22436/jnsa.010.08.15
} 
Afterwards Salimi et al. [20] and Hussain et al. [15, 16] modified the notions of $\alpha$-admissible mappings and established certain fixed point theorems.

Definition 1.2 ([20]). Let $F$ be a self-mapping on $X$ and $\alpha, \eta: X \times X \rightarrow[0,+\infty)$ be two functions. We say that $F$ is an $\alpha$-admissible mapping with respect to $\eta$ if

$$
x, y \in X, \quad \alpha(x, y) \geqslant \eta(x, y) \quad \Longrightarrow \quad \alpha(F x, F y) \geqslant \eta(F x, F y)
$$

Note that if we take $\eta(x, y)=1$ then this definition reduces to Definition 1.1. Also, if we take $\alpha(x, y)=1$, then we say that $F$ is an $\eta$-subadmissible mapping.

Definition 1.3 ([16]). Let $(X, d)$ be a metric space. Let $\alpha, \eta: X \times X \rightarrow[0, \infty)$ and $F: X \rightarrow X$ be functions. We say $F$ is an $\alpha-\eta$-continuous mapping on $(X, d)$, if for given $x \in X$ and sequence $\left\{x_{n}\right\}$ with

$$
x_{n} \rightarrow x \text { as } n \rightarrow \infty, \alpha\left(x_{n}, x_{n+1}\right) \geqslant \eta\left(x_{n}, x_{n+1}\right) \forall n \in \mathbb{N} \Longrightarrow F x_{n} \rightarrow F x .
$$

A mapping $F: X \rightarrow X$ is called orbitally continuous at $p \in X$ if $\lim _{n \rightarrow \infty} F^{n} x=p$ implies that $\lim _{n \rightarrow \infty} F^{n} x=$ $F p$. The mapping $F$ is orbitally continuous on $X$ if $F$ is orbitally continuous for all $p \in X$.

Remark 1.4 ([16]). Let $\mathrm{F}: \mathrm{X} \rightarrow \mathrm{X}$ be a self-mapping on an orbitally F-complete metric space $\mathrm{X}$. Define $\alpha, \eta: X \times X \rightarrow[0,+\infty)$ by

$$
\alpha(x, y)=\left\{\begin{array}{ll}
3, & \text { if } x, y \in O(w), \\
0, & \text { otherwise, }
\end{array} \text { and } \eta(x, y)=1,\right.
$$

where $\mathrm{O}(w)$ is an orbit of a point $w \in X$. If $\mathrm{F}: \mathrm{X} \rightarrow \mathrm{X}$ is an orbitally continuous map on $(\mathrm{X}, \mathrm{d})$, then $\mathrm{F}$ is $\alpha$ - $\eta$-continuous on $(X, d)$.

Very recently, Jleli and Samet [19] introduced a new type of contraction called $\Theta$-contraction and established some new fixed point theorems for such contraction in the context of generalized metric spaces.

Definition 1.5. Let $\Theta:(0, \infty) \rightarrow(1, \infty)$ be a function satisfying:

$\left(\Theta_{1}\right) \Theta$ is nondecreasing;

$\left(\Theta_{2}\right)$ for each sequence $\left\{\alpha_{n}\right\} \subseteq R^{+}, \lim _{n \rightarrow \infty} \Theta\left(\alpha_{n}\right)=1$ if and only if $\lim _{n \rightarrow \infty}\left(\alpha_{n}\right)=0$;

$\left(\Theta_{3}\right)$ there exist $0<k<1$ and $l \in(0, \infty]$ such that $\lim _{\alpha \rightarrow 0^{+}} \frac{\Theta(\alpha)-1}{\alpha^{k}}=l$.

A mapping $F: X \rightarrow X$ is said to be $\Theta$-contraction if there exist the function $\Theta$ satisfying $\left(\Theta_{1}\right)-\left(\Theta_{3}\right)$ and a constant $k \in(0,1)$ such that for all $x, y \in X$,

$$
d(F x, F y) \neq 0 \Longrightarrow \Theta(d(F x, F y)) \leqslant[\Theta(d(x, y))]^{k} .
$$

Theorem 1.6 ([19]). Let $(\mathrm{X}, \mathrm{d})$ be a complete metric space and $\mathrm{F}: \mathrm{X} \rightarrow \mathrm{X}$ be a $\Theta$-contraction, then $\mathrm{F}$ has a unique fixed point.

They showed that any Banach contraction is a particular case of $\Theta$-contraction while there are $\Theta$ contractions which are not Banach contractions. To be consistent with Jleli et al. [19], we denote by the $\Psi$ set of all functions $\Theta:(0, \infty) \rightarrow(1, \infty)$ satisfying the above conditions $\left(\Theta_{1}\right)-\left(\Theta_{3}\right)$.

Hussain et al. [17] modified and extended the above result and proved the following fixed point theorem for generalized $\Theta$-contractive condition in the setting of complete metric spaces.

Theorem 1.7 ([17]). Let $(\mathrm{X}, \mathrm{d})$ be a complete metric space and $\mathrm{F}: \mathrm{X} \rightarrow \mathrm{X}$ be a self-mapping. If there exist a function $\Theta \in \Psi$ and positive real numbers $\alpha, \beta, \gamma, \delta$ with $0 \leqslant \alpha+\beta+\gamma+2 \delta<1$ such that

$$
\begin{aligned}
\Theta(d(F x, F y)) \leqslant[\Theta(d(x, y))]^{\alpha} \cdot[\Theta(d(x, F x))]^{\beta} \\
\cdot[\Theta(d(y, F y))]^{\gamma} \cdot\left[\Theta((d(x, F y)+d(y, F x))]^{\delta}\right.
\end{aligned}
$$

for all $x, y \in X$, then $F$ has a unique fixed point. 
Very recently, Ahmad et al. $[2,7]$ used the following weaker condition instead of the condition $\left(\Theta_{3}\right)$ in Definition 1.5.

$\left(\Theta_{3}^{\prime}\right) \Theta$ is continuous on $(0, \infty)$.

Consistent with Ahmad et al. [2], we denote by $\Omega$ the set of all functions satisfying the conditions $\left(\Theta_{1}\right),\left(\Theta_{2}\right)$ and $\left(\Theta_{3}^{\prime}\right)$.

Example 1.8 ([2]). Let $\Theta_{1}(t)=e^{\sqrt{t}}, \Theta_{2}(t)=e^{\sqrt{t e^{t}}}, \Theta_{3}(t)=e^{t}, \Theta_{4}(t)=\cosh t, \Theta_{5}(t)=1+\ln (1+t)$ and $\Theta_{6}(t)=e^{t e^{t}}$ for all $t>0$. Then $\Theta_{1}, \Theta_{2}, \Theta_{3}, \Theta_{4}, \Theta_{5}, \Theta_{6} \in \Omega$.

Example 1.9 ([2]). Note that the conditions $\Theta_{3}$ and $\Theta_{3}^{\prime}$ are independent of each other. Indeed, for $p \geqslant 1$, $\Theta(t)=e^{t^{p}}$ satisfies the conditions $\left(\Theta_{1}\right)$ and $\left(\Theta_{2}\right)$ but it does not satisfy $\left(\Theta_{3}\right)$, while it satisfies the condition $\left(\Theta_{3}^{\prime}\right)$. Therefore $\Omega \nsubseteq \Psi \Psi$. Again for $p>1, m \in\left(0, \frac{1}{p}\right) \Theta(t)=1+t^{m}(1+[t])$ where $[t]$ denotes the integral part of $t$, satisfies the conditions $\left(\Theta_{1}\right)$ and $\left(\Theta_{2}\right)$ but it does not satisfy $\left(\Theta_{3}^{\prime}\right)$, while it satisfies the condition $\left(\Theta_{3}\right)$ for any $k \in\left(\frac{1}{p}, 1\right)$. Therefore $\Psi \nsubseteq \Omega$. Also, if we take $\Theta(t)=e^{\sqrt{t}}$, then $\Theta \in \Psi$ and $\Theta \in \Omega$. Therefore $\Psi \cap \Omega \neq \emptyset$.

In this paper, we apply the same weaker condition $\left(\Theta_{3}^{\prime}\right)$ to obtain some new fixed point theorems in the context of complete metric spaces.

\section{Main results}

In this section, we define $\alpha-\eta-\Theta$-contraction for a new family of functions $\Omega$ and establish certain fixed point theorems in the context of complete metric spaces.

Definition 2.1. Let $(X, d)$ be a metric space and $F$ be a self-mapping on $X$. Also suppose that $\alpha, \eta: X \times X \rightarrow$ $[0,+\infty)$ be two functions. We say that $F$ is $\alpha-\eta-\Theta$-contraction if for $x, y \in X$ with $\eta(x, F x) \leqslant \alpha(x, y)$ and $\mathrm{d}(\mathrm{Fx}, \mathrm{Fy})>0$, we have

where $\Theta \in \Omega$ and $k \in(0,1)$.

$$
\Theta(d(F x, F y)) \leqslant[\Theta(d(x, y))]^{k},
$$

Theorem 2.2. Let $(\mathrm{X}, \mathrm{d})$ be a complete metric space. Let $\mathrm{F}: \mathrm{X} \rightarrow \mathrm{X}$ be a self-mapping satisfying the following assertions:

(i) $\mathrm{F}$ is $\alpha$-admissible mapping with respect to $\eta$;

(ii) $\mathrm{F}$ is $\alpha-\eta-\Theta-$ contraction;

(iii) there exists $\mathrm{x}_{0} \in \mathrm{X}$ such that $\alpha\left(\mathrm{x}_{0}, \mathrm{~F} \mathrm{x}_{0}\right) \geqslant \eta\left(\mathrm{x}_{0}, \mathrm{Fx_{0 }}\right)$;

(iv) $\mathrm{F}$ is $\alpha-\eta$-continuous.

Then $\mathrm{F}$ has a fixed point. Moreover, $\mathrm{F}$ has a unique fixed point when $\alpha(x, y) \geqslant \eta(x, x)$ for all $x, y \in \operatorname{Fix}(\mathrm{T})$.

Proof. Let $x_{0} \in X$ such that $\alpha\left(x_{0}, F x_{0}\right) \geqslant \eta\left(x_{0}, F x_{0}\right)$. For such $x_{0}$, we define the sequence $\left\{x_{n}\right\}$ by $x_{n}=$ $F^{n} x_{0}=F x_{n-1}$. Now, since $F$ is $\alpha$-admissible mapping with respect to $\eta$, then $\alpha\left(x_{0}, x_{1}\right)=\alpha\left(x_{0}, F x_{0}\right) \geqslant$ $\eta\left(x_{0}, F x_{0}\right)=\eta\left(x_{0}, x_{1}\right)$. By continuing this process we have

$$
\eta\left(x_{n-1}, F x_{n-1}\right)=\eta\left(x_{n-1}, x_{n}\right) \leqslant \alpha\left(x_{n-1}, x_{n}\right),
$$

for all $n \in \mathbb{N}$. If there exists $n_{0} \in \mathbb{N}$ such that $x_{n_{0}}=x_{n_{0}+1}$, then $x_{n_{0}}$ is a fixed point of $F$ and we have nothing to prove. Hence, we assume, $x_{n} \neq x_{n+1}$ or $d\left(F x_{n-1}, F x_{n}\right)>0$ for all $n \in \mathbb{N}$. Since, $F$ is $\alpha-\eta-\Theta$-contraction, so we have

$$
1<\Theta\left(d\left(x_{n}, x_{n+1}\right)\right)=\Theta\left(d\left(F x_{n-1}, F x_{n}\right)\right) \leqslant\left[\Theta\left(d\left(x_{n-1}, x_{n}\right)\right)\right]^{k}
$$




$$
\begin{aligned}
& =\left[\Theta\left(d\left(F x_{n-2}, F x_{n-1}\right)\right)\right]^{k} \leqslant\left[\Theta\left(d\left(x_{n-2}, x_{n-1}\right)\right)\right]^{k^{2}} \\
& \vdots \\
& \leqslant\left[\Theta\left(d\left(x_{0}, x_{1}\right)\right)\right]^{k^{n}}
\end{aligned}
$$

for all $n \in \mathbb{N}$. Since $\Theta \in \Omega$, so by taking limit as $n \rightarrow \infty$ in above inequality, we have

$$
\lim _{n \rightarrow \infty} \Theta\left(d\left(x_{n}, x_{n+1}\right)\right)=1 \text {. }
$$

By $\left(\Theta_{2}\right)$, we have

$$
\lim _{n \rightarrow \infty} d\left(x_{n}, x_{n+1}\right)=0 .
$$

Now, we claim that $\left\{x_{n}\right\}_{n=1}^{\infty}$ is a Cauchy sequence. We suppose on the contrary that $\left\{x_{n}\right\}_{n=1}^{\infty}$ is not a Cauchy sequence, then we assume that there exist $\varepsilon>0$ and sequences $\{p(n)\}_{\mathfrak{n}=1}^{\infty}$ and $\{\mathbf{q}(\mathfrak{n})\}_{\mathfrak{n}=1}^{\infty}$ of natural numbers such that for $p(n)>q(n)>n$, we have

$$
d\left(x_{p(n)}, x_{q(n)}\right) \geqslant \varepsilon .
$$

Then

$$
d\left(x_{p(n)-1}, x_{q(n)}\right)<\varepsilon
$$

for all $n \in \mathbb{N}$. So, by triangle inequality and (2.2), we have

$$
\varepsilon \leqslant d\left(x_{p(n)}, x_{q(n)}\right) \leqslant d\left(x_{p(n)}, x_{p(n)-1}\right)+d\left(x_{p(n)-1}, x_{q(n)}\right) \leqslant d\left(x_{p(n)-1}, x_{p(n)}\right)+\varepsilon .
$$

By taking the limit and using inequality (2.2), we get

$$
\lim _{n \rightarrow \infty} d\left(x_{p(n)}, x_{q(n)}\right)=\varepsilon .
$$

From (2.1), we can choose a natural number $\mathfrak{n}_{0} \in \mathbb{N}$ such that

$$
\mathrm{d}\left(\mathrm{x}_{\mathbf{p}(\mathrm{n})}, \mathrm{x}_{\mathrm{p}(\mathrm{n})+1}\right)<\frac{\varepsilon}{4} \text { and } \mathrm{d}\left(\mathrm{x}_{\mathrm{q}(\mathrm{n})}, \mathrm{x}_{\mathrm{q}(\mathrm{n})+1}\right)<\frac{\varepsilon}{4}
$$

for all $n \geqslant n_{0}$. Next, we claim that $F x_{p(n)} \neq F x_{q(n)}$ for all $n \geqslant n_{0}$, that is

$$
\mathrm{d}\left(\mathrm{x}_{\mathbf{p}(\mathrm{n})+1}, \mathrm{x}_{\mathbf{q}(\mathrm{n})+1}\right)=\mathrm{d}\left(\mathrm{F} x_{\mathbf{p}(\mathrm{n})}, \mathrm{F} x_{\mathbf{q}(\mathrm{n})}\right)>0 .
$$

Arguing by contradiction, there exists $\mathrm{N}_{0} \geqslant \mathrm{n}_{0}$ such that $\mathrm{d}\left(\mathrm{x}_{\mathbf{p}(\mathrm{n})+1}, \mathrm{x}_{\mathbf{q}(\mathrm{n})+1}\right)=0$. It follows from (2.1), (2.4), and (2.5) that

$$
\begin{aligned}
\varepsilon & \leqslant d\left(x_{p(n)}, x_{q(n)}\right) \leqslant d\left(x_{p(n)}, x_{p(n)+1}\right)+d\left(x_{p(n)+1}, x_{q(n)+1}\right)+d\left(x_{p(n)+1}, x_{q(n)}\right) \\
& \leqslant \frac{\varepsilon}{4}+0+\frac{\varepsilon}{4}=\frac{\varepsilon}{2},
\end{aligned}
$$

a contradiction. Thus the relation (2.4) holds. Then by the assumption, we get

$$
\Theta\left(d\left(F x_{p(n)}, F x_{q(n)}\right)\right) \leqslant\left[\Theta\left(d\left(x_{p(n)}, x_{q(n)}\right)\right)\right]^{k} .
$$

By taking limit as $n \rightarrow+\infty$ and using $\left(\Theta_{3}^{\prime}\right),(2.3)$ and (2.6), we get

$$
\Theta(\varepsilon) \leqslant[\Theta(\varepsilon)]^{k},
$$

which is a contradiction. Thus $\left\{x_{n}\right\}$ is a Cauchy sequence. Completeness of $X$ ensures that there exists $z \in X$ such that $x_{n} \rightarrow z$ as $n \rightarrow \infty$. Now, since $F$ is $\alpha-\eta$-continuous and $\eta\left(x_{n-1}, x_{n}\right) \leqslant \alpha\left(x_{n-1}, x_{n}\right)$, so

$$
d(z, F z)=\lim _{n \rightarrow \infty} d\left(x_{n}, F x_{n}\right)=\lim _{n \rightarrow \infty} d\left(x_{n}, x_{n+1}\right)=d(z, z)=0 .
$$


Hence, $z$ is a fixed point of F. Now we show the uniqueness of fixed point. We suppose on the contrary that there exists another fixed point $u$ of $F$ distinct from $z$, that is

$$
\mathrm{F} z=z \neq \mathrm{u}=\mathrm{Fu} \text { that is } \mathrm{F} z \neq \mathrm{Fu} \text {. }
$$

Then from assumption of theorem, we obtain

$$
\Theta(d(z, u))=\Theta(d(F z, F u)) \leqslant[\Theta(d(z, u))]^{k},
$$

which is contradiction because $k \in(0,1)$. Thus $z$ is the unique fixed point of $F$.

Theorem 2.3. Let $(\mathrm{X}, \mathrm{d})$ be a complete metric space. Let $\mathrm{F}: \mathrm{X} \rightarrow \mathrm{X}$ be a self-mapping satisfying the following assertions:

(i) $\mathrm{F}$ is an $\alpha$-admissible mapping with respect to $\eta$;

(ii) $\mathrm{F}$ is $\alpha-\eta-\Theta-$ contraction;

(iii) there exists $x_{0} \in X$ such that $\alpha\left(x_{0}, F x_{0}\right) \geqslant \eta\left(x_{0}, F x_{0}\right)$;

(iv) if $\left\{x_{n}\right\}$ is a sequence in $X$ such that $\alpha\left(x_{n}, x_{n+1}\right) \geqslant \eta\left(x_{n}, x_{n+1}\right)$ with $x_{n} \rightarrow x$ as $n \rightarrow \infty$, then either

$$
\eta\left(F x_{n}, F^{2} x_{n}\right) \leqslant \alpha\left(F x_{n}, x\right) \text {, or } \eta\left(F^{2} x_{n}, F^{3} x_{n}\right) \leqslant \alpha\left(F^{2} x_{n}, x\right),
$$

holds for all $\mathrm{n} \in \mathbb{N}$.

Then $\mathrm{F}$ has a fixed point. Moreover, $\mathrm{F}$ has a unique fixed point whenever $\alpha(x, y) \geqslant \eta(x, x)$ for all $x, y \in \operatorname{Fix}(\mathrm{T})$.

Proof. Let $\mathrm{x}_{0} \in \mathrm{X}$ such that $\alpha\left(\mathrm{x}_{0}, \mathrm{Fx}_{0}\right) \geqslant \eta\left(\mathrm{x}_{0}, \mathrm{Fx}_{0}\right)$. As in proof of Theorem 2.2 we can conclude that

$$
\alpha\left(x_{n}, x_{n+1}\right) \geqslant \eta\left(x_{n}, x_{n+1}\right) \text { and } x_{n} \rightarrow x^{*} \text { as } n \rightarrow \infty,
$$

where, $x_{n+1}=T x_{n}$. So, from (iv), either

$$
\eta\left(F x_{n}, F^{2} x_{n}\right) \leqslant \alpha\left(F x_{n}, x^{*}\right) \text { or } \eta\left(F^{2} x_{n}, F^{3} x_{n}\right) \leqslant \alpha\left(F^{2} x_{n}, x^{*}\right),
$$

holds for all $n \in \mathbb{N}$. This implies

$$
\eta\left(x_{n+1}, x_{n+2}\right) \leqslant \alpha\left(x_{n+1}, x\right) \text { or } \eta\left(x_{n+2}, x_{n+3}\right) \leqslant \alpha\left(x_{n+2}, x\right),
$$

holds for all $n \in \mathbb{N}$. Equivalently, there exists a subsequence $\left\{x_{n_{k}}\right\}$ of $\left\{x_{n}\right\}$ such that

$$
\eta\left(x_{n_{k}}, F x_{n_{k}}\right)=\eta\left(x_{n_{k}}, x_{n_{k}+1}\right) \leqslant \alpha\left(x_{n_{k}}, x^{*}\right),
$$

and so from (2.7) we deduce that

$$
\Theta\left(d\left(F x_{n_{k}}, F x^{*}\right)\right) \leqslant\left[\Theta\left(d\left(x_{n_{k}}, x^{*}\right)\right)\right]^{\lambda}<\Theta\left(d\left(x_{n_{k}}, x^{*}\right)\right) .
$$

From $\left(\Theta_{1}\right)$ we have

$$
\mathrm{d}\left(\mathrm{x}_{\mathrm{n}_{\mathrm{k}}+1}, F x^{*}\right)<\mathrm{d}\left(\mathrm{x}_{\mathrm{n}_{\mathrm{k}}}, x^{*}\right) .
$$

By taking limit as $k \rightarrow \infty$ in the above inequality we get $d\left(x^{*}, F x^{*}\right)=0$, i.e., $x^{*}=F x^{*}$. Uniqueness follows similarly as in Theorem 2.2.

Taking $\alpha(x, y)=\eta(x, y)=1$ for all $x, y \in X$, then we deduce the following result as corollary. 
Corollary 2.4. Let $(\mathrm{X}, \mathrm{d})$ be a complete metric space and $\mathrm{F}: \mathrm{X} \rightarrow \mathrm{X}$ be a self-mapping. If for all $\mathrm{x}, \mathrm{y} \in \mathrm{X}$ with $\mathrm{d}(\mathrm{Fx}, \mathrm{Fy})>0$, we have

$$
\Theta(d(F x, F y)) \leqslant[\Theta(d(x, y))]^{k},
$$

where $\mathrm{F} \in \Omega$. Then $\mathrm{F}$ has a fixed point.

Recall that a self-mapping $T$ is said to have the property $P$, if $\operatorname{Fix}\left(T^{n}\right)=F(T)$ for every $n \in \mathbb{N}$.

Theorem 2.5. Let $(\mathrm{X}, \mathrm{d})$ be a complete metric space and $\mathrm{F}: \mathrm{X} \rightarrow \mathrm{X}$ be an $\alpha$-continuous self-mapping. Assume that there exists some $\mathrm{k} \in(0,1)$ such that

$$
\Theta\left(d\left(F x, F^{2} x\right)\right) \leqslant[\Theta(d(x, F x))]^{k},
$$

holds for all $\mathrm{x} \in \mathrm{X}$ with $\mathrm{d}\left(\mathrm{Fx}, \mathrm{F}^{2} \mathrm{x}\right)>0$ where $\Theta \in \Omega$. If $\mathrm{F}$ is an $\alpha$-admissible mapping and there exists $\mathrm{x}_{0} \in \mathrm{X}$ such that $\alpha\left(\mathrm{x}_{0}, \mathrm{Fx}_{0}\right) \geqslant 1$, then $\mathrm{F}$ has the property $\mathrm{P}$.

Proof. Let $x_{0} \in X$ such that $\alpha\left(x_{0}, F x_{0}\right) \geqslant 1$. For such $x_{0}$, we define the sequence $\left\{x_{n}\right\}$ by $x_{n}=F^{n} x_{0}=F x_{n-1}$. Now, since $F$ is $\alpha$-admissible mapping, so $\alpha\left(x_{1}, x_{2}\right)=\alpha\left(F x_{0}, F x_{1}\right) \geqslant 1$. By continuing this process, we have

$$
\alpha\left(x_{n-1}, x_{n}\right) \geqslant 1
$$

for all $n \in \mathbb{N}$. If there exists $n_{0} \in \mathbb{N}$ such that $x_{n_{0}}=x_{n_{0}+1}=F x_{n_{0}}$, then $x_{n_{0}}$ is fixed point of $F$ and we have nothing to prove. Hence, we assume, $x_{n} \neq x_{n+1}$ or $d\left(F x_{n-1}, F^{2} x_{n-1}\right)>0$ for all $n \in \mathbb{N} \cup\{0\}$. From (2.8) we have

$$
1<\Theta\left(d\left(F x_{n-1}, F^{2} x_{n-1}\right)\right) \leqslant\left[\Theta\left(d\left(x_{n-1}, F x_{n-1}\right)\right)\right]^{k},
$$

which implies

$$
1<\Theta\left(d\left(x_{n}, x_{n+1}\right)\right) \leqslant\left[\Theta\left(d\left(x_{n-1}, x_{n}\right)\right)\right]^{k}
$$

and so

$$
1<\Theta\left(d\left(x_{n}, x_{n+1}\right)\right) \leqslant\left[\Theta\left(d\left(x_{n-1}, x_{n}\right)\right)\right]^{k} .
$$

Therefore,

$$
1<\Theta\left(d\left(x_{n}, x_{n+1}\right)\right) \leqslant\left[\Theta\left(d\left(x_{n-1}, x_{n}\right)\right)\right]^{k} \leqslant\left[\Theta\left(d\left(x_{n-2}, x_{n-1}\right)\right)\right]^{k^{2}} \leqslant \cdots \leqslant\left[\Theta\left(d\left(x_{0}, x_{1}\right)\right)\right]^{k^{n}} .
$$

By taking limit as $n \rightarrow \infty$ in above inequality, we have $\lim _{n \rightarrow \infty} \Theta\left(d\left(x_{n}, x_{n+1}\right)\right)=1$, and since $\Theta \in \Omega$ we obtain

$$
\lim _{n \rightarrow \infty} d\left(x_{n}, x_{n+1}\right)=0 .
$$

Now, we claim that $\left\{x_{n}\right\}_{\mathfrak{n}=1}^{\infty}$ is a Cauchy sequence. We suppose on the contrary that $\left\{x_{n}\right\}_{n=1}^{\infty}$ is not Cauchy then we assume there exist $\varepsilon>0$ and sequences $\{p(n)\}_{\mathfrak{n}=1}^{\infty}$ and $\{\mathbf{q}(\mathfrak{n})\}_{\mathfrak{n}=1}^{\infty}$ of natural numbers such that for $p(n)>q(n)>n$, we have

$$
d\left(x_{p(n)}, F x_{q(n)-1}\right)=d\left(x_{p(n)}, x_{q(n)}\right) \geqslant \varepsilon .
$$

Then

$$
\mathrm{d}\left(\mathrm{x}_{\mathrm{p}(\mathrm{n})-1}, F x_{\mathrm{q}(\mathrm{n})-1}\right)<\varepsilon
$$

for all $n \in \mathbb{N}$. So, by triangle inequality and (2.10), we have

$$
\varepsilon \leqslant d\left(x_{p(n)}, F x_{q(n)-1}\right) \leqslant d\left(x_{p(n)}, x_{p(n)-1}\right)+d\left(x_{p(n)-1}, F x_{q(n)-1}\right) \leqslant d\left(x_{p(n)}, x_{p(n)-1}\right)+\varepsilon .
$$

By taking the limit and using inequality (2.9), we get

$$
\lim _{n \rightarrow \infty} d\left(x_{p(n)}, F x_{q(n)-1}\right)=\varepsilon
$$


On the other hand, from (2.9) there exists a natural number $n_{0} \in \mathbb{N}$ such that

$$
\mathrm{d}\left(\mathrm{x}_{\mathrm{p}(\mathrm{n})}, \mathrm{x}_{\mathrm{p}(\mathrm{n})+1}\right)<\frac{\varepsilon}{4} \text { and } \mathrm{d}\left(\mathrm{x}_{\mathbf{q}(\mathrm{n})}, \mathrm{x}_{\mathbf{q}(\mathrm{n})+1}\right)<\frac{\varepsilon}{4}
$$

for all $n \geqslant n_{0}$. Next, we claim that

$$
\mathrm{d}\left(\mathrm{Fx} x_{\mathfrak{p}(\mathfrak{n})}, \mathrm{F}^{2} x_{\mathbf{q}(n)-1}\right)=\mathrm{d}\left(x_{\mathbf{p}(\mathfrak{n})+1}, F x_{\mathbf{q}(\mathfrak{n})}\right)>0
$$

for all $n \geqslant n_{0}$. We suppose on the contrary that there exists $m \geqslant n_{0}$ such that

$$
\mathrm{d}\left(\mathrm{F} x_{\mathrm{p}(\mathrm{m})}, \mathrm{F}^{2} \mathrm{x}_{\mathbf{q}(\mathrm{m})-1}\right)=\mathrm{d}\left(\mathrm{x}_{\mathrm{p}(\mathrm{m})+1}, \mathrm{~F} \mathrm{x}_{\mathrm{q}(\mathrm{m})}\right)=0 .
$$

Then from (2.11), (2.12) and (2.13), we have

$$
\begin{aligned}
\varepsilon & \leqslant d\left(x_{p(m)}, F x_{q(m)-1}\right) \leqslant d\left(x_{p(m)}, x_{p(m)+1}\right)+d\left(x_{p(m)+1}, F x_{q(m)-1}\right) \\
& \leqslant d\left(x_{p(m)}, x_{p(m)+1}\right)+d\left(x_{p(m)+1}, x_{q(m)+1}\right)+d\left(x_{q(m)+1}, F x_{q(m)-1}\right) \\
& =d\left(x_{p(m)}, x_{p(m)+1}\right)+d\left(x_{p(m)+1}, F x_{q(m)}\right)+d\left(x_{q(m)+1}, x_{q(m)}\right) \\
& <\frac{\varepsilon}{4}+0+\frac{\varepsilon}{4}=\frac{\varepsilon}{2},
\end{aligned}
$$

which is a contradiction. Thus

$$
\begin{gathered}
d\left(F x_{p(n)}, F^{2} x_{q(n)-1}\right)=d\left(x_{p(n)+1}, F x_{q(n)}\right)>0, \\
\Theta\left(d\left(F x_{p(n)}, F^{2} x_{q(n)-1}\right)\right) \leqslant\left[\Theta\left(d\left(x_{p(n)}, F x_{q(n)-1}\right)\right)\right]^{k},
\end{gathered}
$$

is established which further implies that

$$
\Theta\left(d\left(x_{p(n)+1}, x_{q(n)+1}\right)\right) \leqslant\left[\Theta\left(d\left(x_{p(n)}, x_{q(n)}\right)\right)\right]^{k} .
$$

From $\left(\Theta_{3}\right),(2.10)$ and $(2.14)$, we get

$$
\Theta(\varepsilon) \leqslant[\Theta(\varepsilon)]^{k},
$$

which is a contradiction because $k \in(0,1)$. Thus we proved that $\left\{x_{n}\right\}$ is a Cauchy sequence. Completeness of $X$ ensures that there exists $x^{*} \in X$ such that $x_{n} \rightarrow x^{*}$ as $n \rightarrow \infty$. Now, since $F$ is $\alpha$-continuous and $\alpha\left(x_{n-1}, x_{n}\right) \geqslant 1$ then, $x_{n+1}=F x_{n} \rightarrow F x^{*}$ as $n \rightarrow \infty$. That is, $x^{*}=F x^{*}$. Thus $F$ has a fixed point and $\mathrm{F}\left(\mathrm{F}^{\mathrm{n}}\right)=\mathrm{F}(\mathrm{F})$ for $\mathrm{n}=1$. Let $\mathrm{n}>1$. Assume contrarily that $w \in \mathrm{F}\left(\mathrm{F}^{\mathrm{n}}\right)$ and $w \notin \mathrm{F}(\mathrm{F})$. Then, $\mathrm{d}(w, \mathrm{~F} w)>0$. Now we have

$$
\begin{aligned}
1 & \left.<\Theta(d(w, F w))=\Theta\left(d\left(F\left(F^{n-1} w\right)\right), F^{2}\left(F^{n-1} w\right)\right)\right) \\
& \leqslant\left[\Theta\left(d\left(F^{n-1} w, F^{n} w\right)\right)\right]^{k} \\
& \leqslant\left[\Theta\left(d\left(F^{n-2} w, F^{n-1} w\right)\right)\right]^{k^{2}} \leqslant \cdots \\
& \leqslant[\Theta(d(w, F w))]^{k^{n}} .
\end{aligned}
$$

By taking limit as $n \rightarrow \infty$ in the above inequality we have $\Theta(d(w, F w))=1$. Hence, by $\left(\Theta_{2}\right)$ we get, $\mathrm{d}(w, F w)=0$ which is a contradiction. Therefore, $F\left(F^{n}\right)=F(F)$ for all $n \in \mathbb{N}$.

Let $(X, d, \preceq)$ be a partially ordered metric space. Recall that $F: X \rightarrow X$ is nondecreasing if for all $x, y \in X, x \preceq y$ implies $F(x) \preceq F(y)$ and ordered $\Theta$-contraction if for $x, y \in X$ with $x \preceq y$ and $d(F x, F y)>0$, we have

$$
\Theta(d(F x, F y)) \leqslant[\Theta(d(x, y))]^{k},
$$

where $\Theta \in \Omega$. Fixed point theorems for monotone operators in ordered metric spaces are widely investigated and have found various applications in differential and integral equations (see $[1,14,16,18]$ and references therein). From Theorems 2.2-2.5, we derive the following new results in partially ordered metric spaces. 
Theorem 2.6. Let $(\mathrm{X}, \mathrm{d}, \preceq)$ be a complete partially ordered metric space. Assume that the following assertions hold true:

(i) $\mathrm{F}$ is nondecreasing and ordered $\Theta$-contraction;

(ii) there exists $x_{0} \in \mathrm{X}$ such that $\mathrm{x}_{0} \preceq \mathrm{F} \mathrm{x}_{0}$;

(iii) either for a given $x \in X$ and sequence $\left\{x_{n}\right\}$

$$
\mathrm{x}_{\mathrm{n}} \rightarrow \mathrm{x} \text { as } \mathrm{n} \rightarrow \infty \text { and } \mathrm{x}_{\mathrm{n}} \preceq \mathrm{x}_{\mathrm{n}+1}, \forall \mathrm{n} \in \mathbb{N} \text { we have } \mathrm{F} \mathrm{x}_{\mathrm{n}} \rightarrow \mathrm{Fx},
$$

or if $\left\{x_{n}\right\}$ is a sequence such that $x_{n} \preceq x_{n+1}$ with $x_{n} \rightarrow x$ as $n \rightarrow \infty$, then either

$$
F x_{n} \preceq x \text {, or } F^{2} x_{n} \preceq x,
$$

holds for all $\mathrm{n} \in \mathbb{N}$.

Then $\mathrm{F}$ has a fixed point.

Theorem 2.7. Let $(\mathrm{X}, \mathrm{d}, \preceq)$ be a complete partially ordered metric space. Assume that the following assertions hold true:

(i) $\mathrm{F}$ is nondecreasing and satisfies (2.8) for all $\mathrm{x} \in \mathrm{X}$ with $\mathrm{d}\left(\mathrm{Fx}, \mathrm{F}^{2} \mathrm{x}\right)>0$ where $\Theta \in \Omega$ and $\tau>0$;

(ii) there exists $\mathrm{x}_{0} \in \mathrm{X}$ such that $\mathrm{x}_{0} \preceq \mathrm{F} \mathrm{x}_{0}$;

(iii) for a given $x \in X$ and sequence $\left\{x_{n}\right\}$

$$
\mathrm{x}_{\mathrm{n}} \rightarrow \mathrm{x} \text { as } \mathrm{n} \rightarrow \infty \text { and } \mathrm{x}_{\mathrm{n}} \preceq \mathrm{x}_{\mathrm{n}+1} \text { for all } \mathrm{n} \in \mathbb{N} \text { we have } \mathrm{F} \mathrm{x}_{\mathrm{n}} \rightarrow \mathrm{Fx} .
$$

Then $\mathrm{F}$ has a property $\mathrm{P}$.

As an application of our results proved above, we deduce certain Suzuki-Samet type fixed point theorems.

Theorem 2.8. Let $(\mathrm{X}, \mathrm{d})$ be a complete metric space and $\mathrm{F}$ be a continuous self-mapping on $\mathrm{X}$. If for $\mathrm{x}, \mathrm{y} \in \mathrm{X}$ with $\frac{1}{2} \mathrm{~d}(\mathrm{x}, \mathrm{Fx}) \leqslant \mathrm{d}(\mathrm{x}, \mathrm{y})$ and $\mathrm{d}(\mathrm{Fx}, \mathrm{Fy})>0$ we have

$$
\Theta(d(F x, F y)) \leqslant[\Theta(d(x, y))]^{k},
$$

where $\Theta \in \Omega$. Then $\mathrm{F}$ has a unique fixed point.

Proof. Define, $\alpha, \eta: X \times X \rightarrow[0, \infty)$ by

$$
\alpha(x, y)=d(x, y) \text { and } \eta(x, y)=\frac{1}{2} d(x, y)
$$

for all $x, y \in X$. Now, since $\frac{1}{2} d(x, y) \leqslant d(x, y)$ for all $x, y \in X$, so $\eta(x, y) \leqslant \alpha(x, y)$ for all $x, y \in X$. That is, conditions (i) and (iii) of Theorem 2.2 hold true. Since $F$ is continuous, so $F$ is $\alpha-\eta$-continuous. Let $\eta(x, F x) \leqslant \alpha(x, y)$ with $d(F x, F y)>0$. Equivalently, if $\frac{1}{2} d(x, F x) \leqslant d(x, y)$ with $d(F x, F y)>0$, then we have

$$
\Theta(d(F x, F y)) \leqslant[\Theta(d(x, y))]^{k} .
$$

That is, $F$ is $\alpha-\eta-\Theta$-contraction mapping. Hence, all conditions of Theorem 2.2 hold and $F$ has a unique fixed point. 
Theorem 2.9. Let $(\mathrm{X}, \mathrm{d})$ be a complete metric space and $\mathrm{F}$ be a self-mapping on $\mathrm{X}$. Assume that there exists some $k \in(0,1)$ such that

$$
\frac{1}{2(1+\tau)} d(x, F x) \leqslant d(x, y) \text { implies } \Theta(d(F x, F y)) \leqslant[\Theta(d(x, y))]^{k}
$$

for $\mathrm{x}, \mathrm{y} \in \mathrm{X}$ with $\mathrm{d}(\mathrm{Fx}, \mathrm{Fy})>0$ where $\Theta \in \Omega$. Then $\mathrm{F}$ has a unique fixed point.

Proof. Define $\alpha, \eta: X \times X \rightarrow[0, \infty)$ by

$$
\alpha(x, y)=d(x, y) \text { and } \eta(x, y)=\frac{1}{2(1+\tau)} d(x, y)
$$

for all $x, y \in X$ where $\tau>0$. Now, since, $\frac{1}{2(1+\tau)} d(x, y) \leqslant d(x, y)$ for all $x, y \in X$, so $\eta(x, y) \leqslant \alpha(x, y)$ for all $x, y \in X$. That is, conditions (i) and (iii) of Theorem 2.3 hold true. Let $\left\{x_{n}\right\}$ be a sequence with $x_{n} \rightarrow x$ as $n \rightarrow \infty$. Assume that $d\left(F x_{n}, F^{2} x_{n}\right)=0$ for some $n$. Then $F x_{n}=F^{2} x_{n}$. That is $F x_{n}$ is a fixed point of $F$ and we have nothing to prove. Hence we assume, $F x_{n} \neq F^{2} x_{n}$ for all $n \in \mathbb{N}$. Since $\frac{1}{2(1+\tau)} d\left(F x_{n}, F^{2} x_{n}\right) \leqslant d\left(F x_{n}, F^{2} x_{n}\right)$ for all $n \in \mathbb{N}$, then from (2.15) we get

$$
\Theta\left(d\left(F^{2} x_{n}, F^{3} x_{n}\right)\right) \leqslant\left[\Theta\left(d\left(F x_{n}, F^{2} x_{n}\right)\right)\right]^{k}<\Theta\left(d\left(F x_{n}, F^{2} x_{n}\right)\right),
$$

and so from $\left(\Theta_{1}\right)$ we get,

$$
d\left(F^{2} x_{n}, F^{3} x_{n}\right)<d\left(F x_{n}, F^{2} x_{n}\right) .
$$

Assume there exists $\mathfrak{n}_{0} \in \mathbb{N}$ such that

$$
\eta\left(F x_{n_{0}}, F^{2} x_{n_{0}}\right)>\alpha\left(F x_{n_{0}}, x\right) \text { and } \eta\left(F^{2} x_{n_{0}}, F^{3} x_{n_{0}}\right)>\alpha\left(F^{2} x_{n_{0}}, x\right),
$$

then

$$
\frac{1}{2(1+\tau)} d\left(F x_{n_{0}}, F^{2} x_{n_{0}}\right)>d\left(F x_{n_{0}}, x\right) \text { and } \frac{1}{2(1+\tau)} d\left(F^{2} x_{n_{0}}, F^{3} x_{n_{0}}\right)>d\left(F^{2} x_{n_{0}}, x\right),
$$

so by (2.16) we have,

$$
\begin{aligned}
d\left(F x_{n_{0}}, F^{2} x_{n_{0}}\right) & \leqslant d\left(F x_{n_{0}}, x\right)+d\left(F^{2} x_{n_{0}}, x\right) \\
& <\frac{1}{2(1+\tau)} d\left(F x_{n_{0}}, F^{2} x_{n_{0}}\right)+\frac{1}{2(1+\tau)} d\left(F^{2} x_{n_{0}}, F^{3} x_{n_{0}}\right) \\
& <\frac{1}{2(1+\tau)} d\left(F x_{n_{0}}, F^{2} x_{n_{0}}\right)+\frac{1}{2(1+\tau)} d\left(F x_{n_{0}}, F^{2} x_{n_{0}}\right) \\
& =\frac{2}{2(1+\tau)} d\left(F x_{n_{0}}, F^{2} x_{n_{0}}\right) \leqslant d\left(F x_{n_{0}}, F^{2} x_{n_{0}}\right),
\end{aligned}
$$

which is a contradiction. Hence, either

$$
\eta\left(F x_{n}, F^{2} x_{n}\right) \leqslant \alpha\left(F x_{n}, x\right) \text { or } \eta\left(F^{2} x_{n}, F^{3} x_{n}\right) \leqslant \alpha\left(F^{2} x_{n}, x\right),
$$

holds for all $n \in \mathbb{N}$. That is condition (iv) of Theorem 2.3 holds. Let $\eta(x, F x) \leqslant \alpha(x, y)$. So, $\frac{1}{2(1+\tau)} d(x, F x) \leqslant$ $d(x, y)$. Then from $(2.15)$ we get $\Theta(d(F x, F y)) \leqslant[\Theta(d(x, y))]^{k}$. Hence, all conditions of Theorem 2.3 hold and $F$ has a unique fixed point.

\section{Applications}

Theorem 3.1. Let $(\mathrm{X}, \mathrm{d})$ be a complete metric space and $\mathrm{F}: \mathrm{X} \rightarrow \mathrm{X}$ be a self-mapping satisfying the following assertions:

(i) for $\mathrm{x}, \mathrm{y} \in \mathrm{O}(\mathrm{w})$ with $\mathrm{d}(\mathrm{Fx}, \mathrm{Fy})>0$ we have

$$
\Theta(d(F x, F y)) \leqslant[\Theta(d(x, y))]^{k},
$$

where $\Theta \in \Omega$ and $\mathrm{k} \in(0,1)$; 
(ii) $\mathrm{F}$ is an orbitally continuous function.

Then $\mathrm{F}$ has a fixed point. Moreover, $\mathrm{F}$ has a unique fixed point when $\mathrm{Fix}(\mathrm{F}) \subseteq \mathrm{O}(w)$.

Proof. Define $\alpha, \eta: X \times X \rightarrow[0,+\infty)$ by

$$
\alpha(x, y)=\left\{\begin{array}{ll}
3, & \text { if } x, y \in O(w), \\
0, & \text { otherwise, }
\end{array} \text { and } \eta(x, y)=1,\right.
$$

where $\mathrm{O}(w)$ is an orbit of a point $w \in X$. From Remark 1.4 we know that $\mathrm{F}$ is an $\alpha$ - $\eta$-continuous mapping. Let $\alpha(x, y) \geqslant \eta(x, y)$, then $x, y \in O(w)$. So $F x, F y \in O(w)$. That is, $\alpha(F x, F y) \geqslant \eta(F x, F y)$. Therefore, $\mathrm{F}$ is an $\alpha$-admissible mapping with respect to $\eta$. Since $w, F w \in O(w)$, then $\alpha(w, F w) \geqslant \eta(w, F w)$. Let $\alpha(x, y) \geqslant \eta(x, F x)$ and $d(F x, F y)>0$. Then, $x, y \in O(w)$ and $d(F x, F y)>0$. Therefore from (i) we have

$$
\Theta(d(F x, F y)) \leqslant[\Theta(d(x, y))]^{k},
$$

which implies $F$ is $\alpha-\eta-\Theta$-contraction mapping. Hence, all conditions of Theorem 2.2 hold true and $F$ has a fixed point. If $\operatorname{Fix}(F) \subseteq O(w)$, then, $\alpha(x, y) \geqslant \eta(x, y)$ for all $x, y \in \operatorname{Fix}(F)$ and so from Theorem $2.2 F$ has a unique fixed point.

Theorem 3.2. Let $(\mathrm{X}, \mathrm{d})$ be a complete metric space and $\mathrm{F}: \mathrm{X} \rightarrow \mathrm{X}$ be a self-mapping satisfying the following assertions:

(i) for $x \in \mathrm{X}$ with $\mathrm{d}\left(\mathrm{F} x, \mathrm{~F}^{2} \mathrm{x}\right)>0$ we have,

$$
\Theta\left(d\left(F x, F^{2} x\right)\right) \leqslant[\Theta(d(x, F x))]^{k},
$$

where $\Theta \in \Omega$ and $k \in(0,1)$;

(ii) $\mathrm{F}$ is an orbitally continuous function.

Then $\mathrm{F}$ has the property $\mathrm{P}$.

Proof. Define $\alpha: X \times X \rightarrow[0,+\infty)$ by

$$
\alpha(x, y)= \begin{cases}1, & \text { if } x \in \mathrm{O}(w), \\ 0, & \text { otherwise, }\end{cases}
$$

where $w \in X$. Let $\alpha(x, y) \geqslant 1$, then $x, y \in O(w)$. So Fx, Fy $\in \mathrm{O}(w)$. That is, $\alpha(F x, F y) \geqslant 1$. Therefore, $F$ is $\alpha$-admissible mapping. Since $w, F w \in O(w)$, so $\alpha(w, F w) \geqslant 1$. By Remark 1.4 we conclude that $F$ is $\alpha$-continuous mapping. If $x \in X$ with $d\left(F x, F^{2} x\right)>0$, then, from (i) we have

$$
\Theta\left(d\left(F x, F^{2} x\right)\right) \leqslant[\Theta(d(x, F x))]^{k} .
$$

Thus all conditions of Theorem 2.5 hold true and $F$ has the property $P$.

We can easily deduce following results involving integral inequalities.

Theorem 3.3. Let $(\mathrm{X}, \mathrm{d})$ be a complete metric space and $\mathrm{F}$ be a continuous self-mapping on $\mathrm{X}$. If for $\mathrm{x}, \mathrm{y} \in \mathrm{X}$ with

$$
\int_{0}^{d(x, F x)} \rho(t) d t \leqslant \int_{0}^{d(x, y)} \rho(t) d t \text { and } \int_{0}^{d(F x, F y)} \rho(t) d t>0,
$$

we have

$$
\Theta\left(\int_{0}^{\mathrm{d}(F x, F y)} \rho(t) d t\right) \leqslant\left[\Theta\left(\int_{0}^{d(x, y)} \rho(t) d t\right)\right]^{k},
$$

where $\Theta \in \Omega, k \in(0,1)$ and $\rho:[0, \infty) \rightarrow[0, \infty)$ is a Lebesgue-integrable mapping satisfying $\int_{0}^{\varepsilon} \rho(t) d t>0$ for $\varepsilon>0$. Then $\mathrm{F}$ has a unique fixed point. 
Theorem 3.4. Let $(\mathrm{X}, \mathrm{d})$ be a complete metric space and $\mathrm{F}$ be a self-mapping on $\mathrm{X}$. Assume that there exists some $\mathrm{k} \in(0,1)$ such that

$$
\frac{1}{2(1+\tau)} \int_{0}^{d(x, F x)} \rho(t) d t \leqslant \int_{0}^{d(x, y)} \rho(t) d t \Rightarrow \Theta\left(\int_{0}^{d(F x, F y)} \rho(t) d t\right) \leqslant\left[\Theta\left(\int_{0}^{d}(x, y) \rho(t) d t\right)\right]^{k}
$$

for $x, y \in X$ with $\int_{0}^{d(F x, F y)} \rho(t) d t>0$ where $\Theta \in \Omega$ and $\rho:[0, \infty) \rightarrow[0, \infty)$ is a Lebesgue-integrable mapping satisfying $\int_{0}^{\varepsilon} \rho(\mathrm{t}) \mathrm{dt}>0$ for $\varepsilon>0$. Then $\mathrm{F}$ has a unique fixed point.

Theorem 3.5. Let $(\mathrm{X}, \mathrm{d})$ be a complete metric space and $\mathrm{F}: \mathrm{X} \rightarrow \mathrm{X}$ be a self-mapping satisfying the following assertions:

(i) for $x, y \in O(w)$ with $\int_{0}^{d(F x, F y)} \rho(t) d t>0$ we have

$$
\Theta\left(\int_{0}^{d(F x, F y)} \rho(t) d t\right) \leqslant\left[\Theta\left(\int_{0}^{d(x, y)} \rho(t) d t\right)\right]^{k},
$$

where $\Theta \in \Omega, k \in(0,1)$ and $\rho:[0, \infty) \rightarrow[0, \infty)$ is a Lebesgue-integrable mapping satisfying $\int_{0}^{\varepsilon} \rho(t) d t>0$ for $\varepsilon>0$;

(ii) $\mathrm{F}$ is an orbitally continuous function.

Then $\mathrm{F}$ has a fixed point. Moreover, $\mathrm{F}$ has a unique fixed point when $\operatorname{Fix}(\mathrm{F}) \subseteq \mathrm{O}(w)$.

Theorem 3.6. Let $(\mathrm{X}, \mathrm{d})$ be a complete metric space and $\mathrm{F}: \mathrm{X} \rightarrow \mathrm{X}$ be a self-mapping satisfying the following assertions:

(i) for $x \in X$ with $\int_{0}^{\mathrm{d}\left(\mathrm{Fx}, \mathrm{F}^{2} \mathrm{x}\right)} \rho(\mathrm{t}) \mathrm{dt}>0$ we have

$$
\Theta\left(\int_{0}^{d\left(F x, F^{2} x\right)} \rho(t) d t\right) \leqslant\left[\Theta\left(\int_{0}^{d(x, F x)} \rho(t) d t\right)\right]^{k},
$$

where $\Theta \in \Omega, k \in(0,1)$ and $\rho:[0, \infty) \rightarrow[0, \infty)$ is a Lebesgue-integrable mapping satisfying $\int_{0}^{\varepsilon} \rho(\mathrm{t}) \mathrm{dt}>0$ for $\varepsilon>0$;

(ii) $\mathrm{F}$ is an orbitally continuous function.

Then $\mathrm{F}$ has the property $\mathrm{P}$.

\section{Acknowledgment}

This article was funded by the Deanship of Scientific Research (DSR), King Abdulaziz University, Jeddah. Therefore, first author acknowledges with thanks DSR, KAU for financial support.

\section{References}

[1] R. P. Agarwal, N. Hussain, M. A. Taoudi, Fixed point theorems in ordered Banach spaces and applications to nonlinear integral equations, Abstr. Appl. Anal., 2012 (2012), 15 pages. 1, 2

[2] J. Ahmad, A. E. Al-Mazrooei, Y. J. Cho, Y.-O. Yang, Fixed point results for generalized $\Theta$-contractions, J. Nonlinear Sci. Appl., 10 (2017), 2350-2358. 1, 1.8, 1.9

[3] J. Ahmad, A. Al-Rawashdeh, A. Azam, Fixed point results for $\{\alpha, \xi\}$-expansive locally contractive mappings, J. Inequal. Appl., 2014 (2014), 10 pages.

[4] J. Ahmad, A. Al-Rawashdeh, A. Azam, New fixed point theorems for generalized F-contractions in complete metric spaces, Fixed Point Theory Appl., 2015 (2015), 18 pages.

[5] J. Ahmad, N. Hussain, A. Azam, M. Arshad, Common fixed point results in complex valued metric space with applications to system of integral equations, J. Nonlinear Convex Anal., 29 (2015), 855-871. 
[6] A. Al-Rawashdeh, J. Ahmad, Common fixed point theorems for JS-contractions, Bull. Math. Anal. Appl., 8 (2016), 12-22.

[7] Z. Aslam, J. Ahmad, N. Sultana, New common fixed point theorems for cyclic compatible contractions, J. Math. Anal., 8 (2017), 1-12. 1

[8] S. Banach, Sur les opérations dans les ensembles abstraits et leur application aux équations intégrales, Fund. Math., 3 (1922), 133-181. 1

[9] V. Berinde, General constructive fixed point theorems for Ćirić-type almost contractions in metric spaces, Carpathian J. Math., 24 (2008), 10-19.

[10] L. B. Ćirić, A generalization of Banach's contraction principle, Proc. Amer. Math. Soc., 45 (1974), $267-273$.

[11] M. Edelstein, On fixed and periodic points under contractive mappings, J. London Math. Soc., 37 (1962), 74-79.

[12] N. Hussain, J. Ahmad, A. Azam, Generalized fixed point theorems for multi-valued $\alpha$ - $\psi$-contractive mappings, J. Inequal. Appl., 2014 (2014), 15 pages.

[13] N. Hussain, J. Ahmad, L. Ćirić, A. Azam, Coincidence point theorems for generalized contractions with application to integral equations, Fixed Point Theory Appl., 2015 (2015), 13 pages. 1

[14] N. Hussain, S. Al-Mezel, P. Salimi, Fixed points for $\psi$-graphic contractions with application to integral equations, Abstr. Appl. Anal., 2013 (2013), 11 pages. 2

[15] N. Hussain, M. A. Kutbi, S. Khaleghizadeh, P. Salimi, Discussions on recent results for $\alpha-\psi$-contractive mappings, Abstr. Appl. Anal., 2014 (2014), 13 pages. 1

[16] N. Hussain, M. A. Kutbi, P. Salimi, Fixed point theory in $\alpha$-complete metric spaces with applications, Abstr. Appl. Anal., 2014 (2014), 11 pages. 1, 1.3, 1.4, 2

[17] N. Hussain, V. Parvaneh, B. Samet, C. Vetro, Some fixed point theorems for generalized contractive mappings in complete metric spaces, Fixed Point Theory Appl., 2015 (2015), 17 pages. 1, 1, 1.7

[18] N. Hussain, M. A. Taoudi, Krasnosel'skii-type fixed point theorems with applications to Volterra integral equations, Fixed Point Theory Appl., 2013 (2013), 16 pages. 2

[19] M. Jleli, B. Samet, A new generalization of the Banach contraction principle, J. Inequal. Appl., 2014 (2014), 8 pages. 1, $1.6,1$

[20] P. Salimi, A. Latif, N. Hussain, Modified $\alpha-\psi$-contractive mappings with applications, Fixed Point Theory Appl., 2013 (2013), 19 pages. $1,1.2$

[21] B. Samet, C. Vetro, P. Vetro, Fixed point theorems for $\alpha \psi$-contractive type mappings, Nonlinear Anal., 75 (2012), 2154-2165. 1, 1.1 